not a popular mix among students as evidenced in the infamous editorial by Warlow entitled 'Teaching medical students neurology - an old codger's view ${ }^{\prime} .{ }^{[1]}$ Inspirational teachers can go a long way in enhancing student neurology learning and there is considerable truth to the age old adage 'you don't forget a good teacher'. However, not all students are fortunate enough to have inspirational teachers, and as such they may fall short of the competencies required of them regarding Neurology. It is remarkably easy for students to survive medical school and avoid one or two select subjects, but this is to the major detriment of patient care when concerning a central medical discipline such as neurology.

A social media survey $(n=624)$ into why students had this attitude to neurology was carried out by ourselves, and unsurprisingly it came down to the fact that Neurology is perceived harder to learn and thus score highly in exams compared with other specialities (renal medicine being the exception). Effectively medical students display 'exam point seeking behavior' and they manage their time to allow emphasis on subjects they find easier.

The survey found that students respond better to resources produced by other students, particularly for neurology and renal medicine. The main reason being students feel that they produced resources and have sorted out the superfluous information that may be present in nonstudent produced resources, hence streamlining their study.

We decided to produce a document that has gone on to be one of the most downloaded medical education documents of 2013/14. The overriding feedback we received regarding the resource, is it engages students in practical neurology, namely assessing and treating patients rather than theory, which students find time consuming and thus avoid. Hence neurology teaching should aim to engage students practically, and through this practical engagement pass on the knowledge required to be a safe competent doctor. Importantly, this resource reaches rural to urban-based medical students.

\title{
Accessible knowledge for tomorrow's surgeons and doctors
}

Within this internationally successful project, we have determined one of the central keys, to engaging students in general, is to engage students completely in the application of practical medicine. Importantly, it engages students across the world, in rural and urban environments.

Thomas I. Lemon, Drew Davies Sir, Undergraduate medical education and neurology are 
Address for correspondence: Dr. Thomas I Lemon, University Hospital of Wales, Cardiff, United Kingdom. E-mail: lemonti@cf.ac.uk

\section{Reference}

1. Warlow C. Teaching medical students clinical neurology: An old codger's view. Pract Neurol 2005;5:318-21

\begin{tabular}{|l|l|}
\hline \multicolumn{2}{|c|}{ Access this article online } \\
\hline Quick Response Code: & Website: \\
\hline & www.ruralneuropractice.com \\
\cline { 2 - 2 } & \\
\hline & \\
\hline
\end{tabular}

